\title{
Touch Imprint Cytology and Stereotactically-Guided Core Needle Biopsy of Suspicious Breast Lesions: 15-Year Follow-up
}

\author{
Abrollzytologie und stereotaktische Stanzbiopsien auffälliger Befunde der Brust: \\ 15-Jahres-Follow-up
}

Authors

Affiliations
R. Schulz-Wendtland ${ }^{1}$, P. A. Fasching ${ }^{2}$, M. R. Bani², M. P. Lux², S. Jud ${ }^{2}$, C. Rauh² ${ }^{2}$ C. Bayer ${ }^{2}$, D. L. Wachter ${ }^{3}$, A. Hartmann ${ }^{3}$, M. W. Beckmann'2, M. Uder ${ }^{4}$, C. R. Loehberg ${ }^{2}$

The affiliations are listed at the end of the article.
Key words

- breast lesions

breast diagnostics

- touch imprint cytology

- core-needle biopsy

Schlüsselwörter

- Brustläsionen

- Brustdiagnostik

- Abrollzytologie

- Stanzbiopsie received 2.9.2015

revised 27.11.2015

accepted 29.11.2015

\section{Bibliography}

DOI http://dx.doi.org/

10.1055/s-0041-110395

Geburtsh Frauenheilk 2016; 76 :

59-64 (c) Georg Thieme

Verlag KG Stuttgart · New York ·

ISSN 0016-5751

Correspondence

Prof. Dr. med. Rüdiger

Schulz-Wendtland

Gynäkologische Radiologie

Radiologisches Institut des

Universitätsklinikums Erlangen

Universitätsstraße 21-23

91054 Erlangen

ruediger.schulz-wendtland@

uk-erlangen.de

\section{Abstract}

$\nabla$

Introduction: Stereotactically-guided core needle biopsies (CNB) of breast tumours allow histological examination of the tumour without surgery. Touch imprint cytology (TIC) of CNB promises to be useful in providing same-day diagnosis for counselling purposes and for planning future surgery. Having addressed the issue of accuracy of immediate microscopic evaluation of TIC, we wanted to re-examine the usefulness of this procedure in light of the present health care climate of cost containment by incorporating the surgical 15-year follow-up data and outcome.

Patients and Methods: From January until December 1996 we performed TIC in core needle biopsies of 173 breast tumours in 169 patients, consisting of 122 malignant and 51 benign tumours. Histology of core needle biopsies was proven by surgical histology in all malignant and in 5 benign tumours. Surgical breast biopsy was not performed in 46 patients with 46 benign lesions, as the histological result from the core needle biopsy and the result of the TIC were in agreement with the suspected diagnosis from the complementary breast diagnostics. A 15-year follow-up of these patients followed in 2013 and follow-up data was collected from 40 women.

Results: In the 15-year follow-up of the 40 benign lesions primarily confirmed using CNB and TIC, a diagnostic sensitivity, specificity, positive and negative predictive value and accuracy of $100 \%$ was found.

Conclusion: TIC and stereotactically guided CNB showed excellent long-term follow-up in patients with benign breast lesions. The use of TIC to complement CNB can therefore provide immediate cytological diagnosis of breast lesions.

\section{Zusammenfassung \\ $\nabla$}

Einleitung: Die stereotaktische Stanzbiopsie erlaubt eine histologische Untersuchung von Brusttumoren ohne chirurgischen Eingriff. Die gleichzeitige zytologische Beurteilung von Abrollpräparaten der Stanzzylinder hat den Vorteil, dass das Ergebnis noch am selben Tag vorliegt und für die Beratung und Planung zukünftiger Eingriffe herangezogen werden kann. Nach unserer Untersuchung der mikroskopischen Beurteilung der Abrollzytologie ging es nun darum, die Nützlichkeit dieses Verfahrens im Hinblick auf die aktuelle Debatte um die Kostendämpfung im Gesundheitswesen zu beurteilen. Daten aus dem 15-Jahres-Follow-up von Patientinnen wurden zur Beurteilung des Verfahrens eingesetzt.

Patienten und Methoden: Zwischen Januar und Dezember 1996 wurden 173 stereotaktische Stanzbiopsien von Brusttumoren bei 169 Patientinnen durchgeführt. Die Stanzzylinder wurden zusätzlich zytologisch untersucht. Die Befundung ergab 122 bösartige und 51 gutartige Tumoren. Die Histologie der in der Stanzbiopsie entnommenen Proben wurde bei allen bösartigen und 5 der gutartigen Tumoren chirurgisch bestätigt. Es wurden keine chirurgischen Brustbiopsien bei 46 Patientinnen mit 46 gutartigen Tumoren durchgeführt, da der auf der Stanzbiopsie beruhende histologische Befund sowie das Ergebnis der Abrollzytologie mit der vermuteten Diagnose aus der komplementären Brustdiagnostik übereinstimmte. Das 15-Jahres-Follow-up erfolgte im Jahre 2013 mit der Auswertung der Follow-upDaten von 40 Patientinnen.

Ergebnisse: Beim 15-Jahres-Follow-up von 40 gutartigen Tumoren, die primär mittels stereotaktischer Stanzbiopsie und Abrollzytologie abgeklärt worden waren, betrugen die diagnostische Sensitivität, die Spezifizität, der positive und negative Vorhersagewert und die Genauigkeit jeweils $100 \%$. 
Schlussfolgerung: Sowohl die stereotaktische Stanzbiopsie als auch die Abrollzytologie zeigten bei Patientinnen mit gutartigen Brustveränderungen gute Langzeitergebnisse. Die Abrollzytologie könnte somit eine gute Ergänzung zur stereotaktischen Stanzbiopsie sein, wenn eine sofortige zytologische Diagnose von Brustveränderungen benötigt wird.

\section{Introduction \\ $\nabla$}

The mainstays of breast diagnostics are breast palpation, breast ultrasound and mammography [1]; however the sensitivity and specificity of the individual methods differ. Mammography is only used as a single method for mammography screening worldwide [2]. The increased use of mammograms has led to the frequent detection of breast lesions, which in turn has led to intense investigation to find the most appropriate algorithm in their follow-up evaluation. In addition to open excisional biopsy, various cytological and histological assessment modalities such as fine-needle aspiration cytology (FNAC), stereotactically guided core-needle biopsy (CNB) or touch imprint cytology (TIC) have been analysed [3].

Although FNAC of the mammary gland with its C-classification has greater importance in other countries [4], stereotactically guided CNB with histological B-classification [5] has largely replaced FNAC in Germany [6], since the cytological clarification between non-invasive (in situ) and invasive malignant processes cannot definitely be distinguished [7-9]. The German interdisciplinary S3-guideline for the diagnosis, treatment and follow-up of breast cancer therefore stipulates that breast lesions that are suspicious for malignancy (BI-RADS ${ }^{\mathrm{TM}} 4 / 5$ ) should be histologically verified preoperatively [10]. In particular it is stated that FNAC should not be employed as the standard method for diagnostic confirmation of solid breast tumours [10]. The histological diagnostic investigation of unclear findings should be carried out via stereotactically guided $\mathrm{CNB}$, vacuum-assisted biopsy or excision biopsy. CNB and vacuum-assisted biopsy can be performed mammographically and guided by ultrasound [10]. Improved stereotactic technique has also given rise to the performance of stereotactically-guided CNB of non-palpable breast lesions [6, 11-13].

Even though FNAC is less sensitive and specific in comparison to the histopathological assessment of stereotactically guided CNB $[3,14,15]$, it is possible to inform the patient about the diagnosis on the same day, thus avoiding a waiting period which many patients find distressing. Whether TIC taken from stereotactically guided CNB specimens is suitable for immediate cytological evaluation and whether it would provide a good compromise between delivering a fast preliminary result to the patient, at the same time allowing a very sensitive diagnosis with histopathological assessment, was studied at our department in late 1990s [16]. Immediate microscopic evaluation of cytological touch imprints was performed using stereotactically obtained core needle biopsies from 173 breast tumours in 169 patients. In contrast to other studies at the time [17-19], we showed that immediate microscopic evaluation of touch imprints is a less accurate procedure compared to histological evaluation. We therefore came to the conclusion that TIC in combination with stereotacticallyguided CNB should not be integrated into our operational procedures.

Demographic developments and greater individualization, as well as a changed entitlement attitude of patients and changes in the medical economy, continue to stimulate re-evaluation of each method and its utilization in the patient-oriented and cost effective rendering of an accurate diagnosis of benign or malignant. TIC promises to be useful in providing same-day diagnosis for counselling purposes and for planning future surgery. It may also reduce anxiety in patients with benign lesions and expedite the diagnosis and assessment of treatment options in patients with breast cancer [20,21].

Having addressed the issue of the accuracy of immediate microscopic evaluation of TIC [16], we wanted to re-examine the usefulness of this procedure in light of the present health care climate of cost containment by incorporating the surgical 15-year follow-up data and outcome.

\section{Patients and Methods}

$\nabla$

\section{Patient recruitment and follow-up}

From January until December 1996, stereotactically guided CNB was performed on 169 patients with a total of 173 breast lesions at the Department of Gynaecological Radiology, University Hospital of Erlangen, Germany. The lesions were evaluated histologically and cytologically.

The 15-year follow-up data of the patients with a benign lesion was collected in 2013 ( Fig. 1). Databanks from the Department of Gynaecological Radiology in the Institute of Radiology as well as the Department of Gynaecology and Obstetrics were surveyed. The registry office performed a search for patients whose followup data could not be collected using the databanks and these patients were contacted personally.

\section{Indication and performance of stereotactically guided CNB}

The indications for stereotactically guided CNB were:

1. Clarification of unclear, rather benign, sonographically-definable lesions without an indication for surgery (BI-RADS ${ }^{\text {TM }} 4$ ).

2. Perioperative histological confirmation of a carcinoma with a suspicious sonographically identifiable lesion for the preoperative planning of the surgical technique or incision in the case of breast-conserving treatment (BI-RADS ${ }^{\mathrm{TM}} 5$ ).

The CNB were performed using a CNB instrument from BARD Angiomed $^{\mathrm{TM}}$ (now BIPTM) by 5 medical doctors supervised by a specialist. The biopsy needles used were $10 \mathrm{~cm}$ long and had a $2.1 \mathrm{~mm}$ (14 gauge) diameter. The standard punch depth was defined as $2.2 \mathrm{~cm}$ and the punch speed of the device used by us was $100 \mathrm{~km} / \mathrm{h}$.

After a detailed explanation, the patient was correctly positioned for the biopsy. Oncological aspects were taken into account when choosing the puncture site and direction so that a carcinoma in the puncture canal could also be removed where possible. Local anaesthesia of the skin was carried out under sterile conditions. The lesion was targeted via a coaxial cannula (13 gauge) and the biopsy itself was performed under ultrasound guidance using a needle guided tangentially to the transducer $(7.5 \mathrm{MHz})$. The posi- 


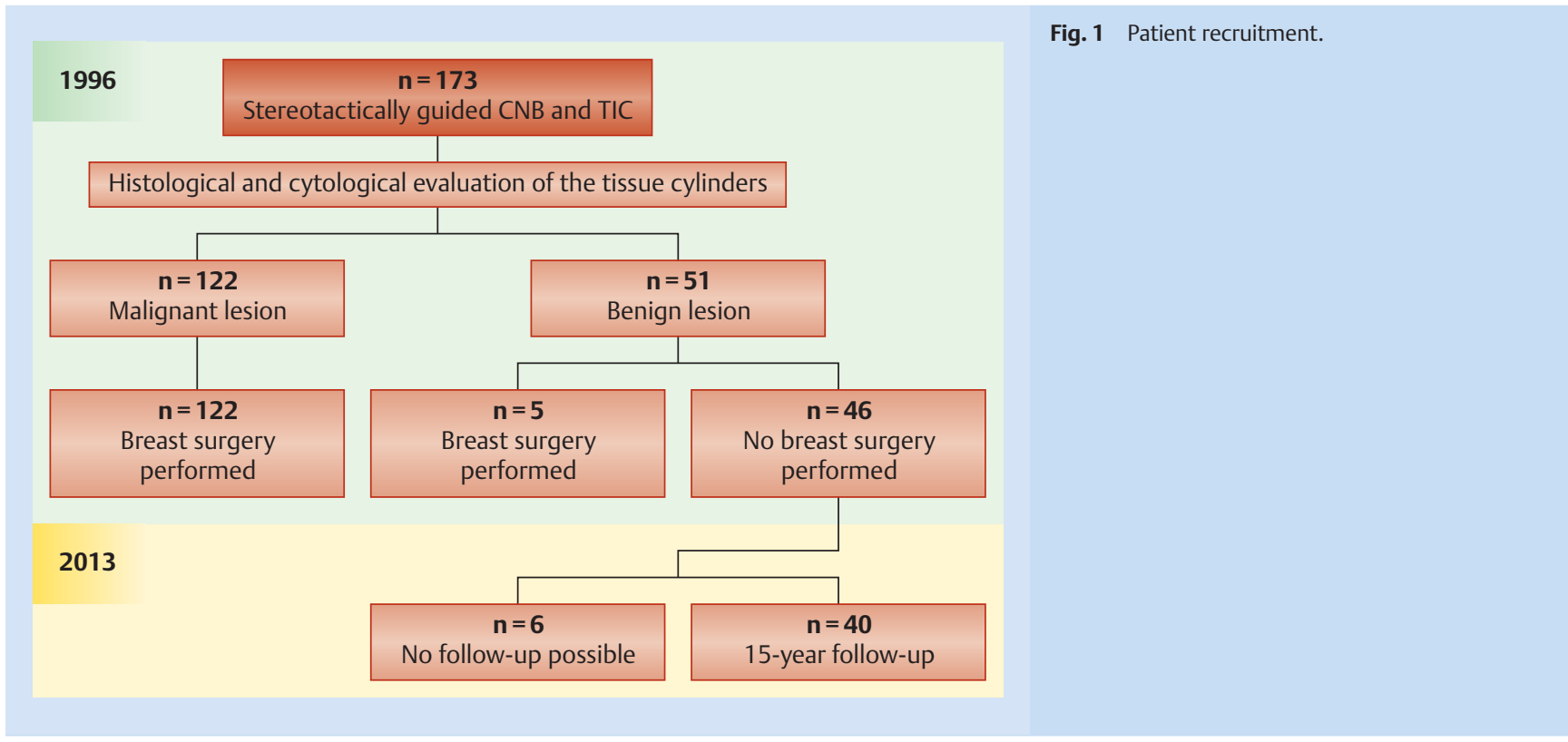

tion of the biopsy needle before and after the biopsy was documented. For methodical reasons, only 2 core biopsy specimens were removed from each respective lesion. After the intervention, the puncture incision was closed with an adhesive strip and covered with a small dressing. The patient then applied pressure to the puncture area herself for ca. 30 minutes to prevent secondary bleeding.

\section{Preparation of the cytological touch imprint specimens}

Two TICs were immediately prepared from the tissue cylinders removed under stereotactic guidance. One specimen was fixed for the subsequent staining according to Papanicolaou, the other was air dried in preparation for May-Giemsa-Grünwald staining according to standard procedure. The specimen stained according to Papanicolaou could be assessed cytologically after 20-45 minutes, the May-Giemsa-Grünwald specimen after 30-90 minutes. The five categories of the National Health Service breast screening program guidelines (NHSBSP) were used for reporting the results [22]: $\mathrm{C} 1$, inadequate; $\mathrm{C} 2$, benign; $\mathrm{C}$, atypia probably benign; $\mathrm{C} 4$, probably malignant; $\mathrm{C} 5$, malignant. Imprints categorized as $\mathrm{C} 5$ or $\mathrm{C} 4$ were considered malignant whilst imprints classified as $\mathrm{C} 2$ or $\mathrm{C} 3$ were scored as benign.

\section{Histological evaluation of the tissue cylinders}

The tissue cylinders were brought to the local Department of Pathology immediately after preparation of the touch imprint specimens. Here, one cylinder was prepared for frozen section analysis and the other was embedded in paraffin according to standard procedure. The frozen- and paraffin sections were stained with haematoxylin-eosin stain. Histological assessment of frozen sections can be performed after 10 minutes and after 4 hours for paraffin sections (automated paraffin embedding).

\section{Statistical analysis}

The histology of the surgical specimens was compared with those of the CNB with regard to sensitivity and positive predictive value. A negative predictive value and specificity in non-operated, benign lesions was evaluated under the assumption that the histology of the CNB correlated with the histology of the surgical specimen. The histology of the CNB was compared with the cytological diagnosis to evaluate the diagnostic value of TIC compared to the histology of the punch cylinder. False-negative CNB results from a failed puncture were classified as negative to ensure direct comparison of the methods.

\section{Results}

$\boldsymbol{\nabla}$

Study population and histology of the analysed tumours A total of 173 ultrasound-guided CNB were performed in 169 patients in 1996. The mean age of the patients was 54 years (minimum 21 years, maximum 92 years); the size of the lesions ranged from $0.9-1.8 \mathrm{~cm}$, median $1.4 \mathrm{~cm}$.

From a total of 173 lesions, all carcinomas $(n=122)$ and 5 benign lesions were clarified surgically and histologically. A surgical breast biopsy was avoided for 46 benign lesions as the histological result from the CNB was in agreement with the suspected diagnosis from the complementary breast diagnostics.

\section{Results of the CNB with regard to the surgical specimen histology (1996)}

Based on the surgical-histological results, histology of the CNB reached a sensitivity of $99.2 \%$ and a positive predictive value of $100 \%$ as well as a negative predictive value of $83.3 \%$ (Table 1 ). Assuming that all CNB which were found to be negative were also surgically-histologically benign, it reached a sensitivity of $99.2 \%$, a negative predictive value of $98.1 \%$, specificity and positive predictive value of $100 \%$. The diagnostic accuracy was 99.4 and 99.2\% ( $\odot$ Tables 1 and 2 ).

\section{Results of TIC with regard to the surgical specimen histology (1996)}

In assessing the diagnostic value of TIC compared with histology of the CNB, the cytological results were compared with those of the CNB since cytology can only assess what the tissue cylinder from the CNB contains. Cytology reached a sensitivity of $77.5 \%$, specificity of $95.9 \%$, positive predictive value of $97.8 \%$ and negative predictive value of $63.5 \%$ with a diagnostic accuracy of $82.8 \%$ 
Table 1 Results of the stereotactically-guided core needle biopsies (CNB) with regard to the surgical specimen histology $(n=125)$ in 1996.

\begin{tabular}{|c|c|c|c|c|c|}
\hline & Positive & Negative & Not assessable & & \\
\hline Malignant & 119 & 1 & (2) & 120 & Sensitivity: $99.2 \%$ \\
\hline \multirow[t]{3}{*}{ Benign } & 0 & 5 & 0 & 5 & Specificity: $100 \%$ \\
\hline & 119 & 6 & (2) & 125 & \\
\hline & Positive predictive value: $100 \%$ & Neqative predictive value: $83.3 \%$ & & & Accuracy: $99.2 \%$ \\
\hline
\end{tabular}

Table 2 Histology of the stereotactically-guided core needle biopsies (CNB) $(n=173)$ in 1996.

\begin{tabular}{|llllrl|} 
& Positive & Negative & Not assessable & \\
Malignant & 119 & 1 & $(2)$ & 120 & Sensitivity: $99.20 \%$ \\
\hline Benign & 0 & 51 & 0 & 51 & Specificity: $100 \%$ \\
\hline & 119 & 52 & $(2)$ & 171 & Accuracy: $99.4 \%$ \\
\hline
\end{tabular}

Table 3 Touch imprint cytology (TIC) of the stereotactically-guided core needle biopsies (CNB) $(n=173)$ in 1996.

\begin{tabular}{|lllllrr|} 
& Positive & Suspect & Negative & \multicolumn{2}{c|}{ Not assessable } \\
Malignant & 87 & 6 & 27 & $(2)$ & 120 & Sensitivity: $77.5 \%$ \\
\hline Benign & 2 & 0 & 47 & $(2)$ & 49 & Specificity: $95.9 \%$ \\
\hline & 89 & 6 & 74 & $(4)$ & 169 & \\
\hline & Positive predictive value: $97.9 \%$ & & negative predictive value: $63.5 \%$ & & Accuracy: $82.8 \%$ \\
\hline
\end{tabular}

Table 4 Results of touch imprint cytology (TIC) with regard to the surgical specimen histology ( $n=125)$ in 1996.

\begin{tabular}{|lllllrl|} 
& positive & suspect & negative & \multicolumn{2}{c}{ not assessable } \\
malignant & 87 & 6 & 27 & $(2)$ & 120 & Sensitivity: $77.5 \%$ \\
\hline benign & 1 & 0 & 4 & 0 & 5 & Specificity: $80 \%$ \\
\hline & 88 & 6 & 31 & $(2)$ & 125 & \\
\hline & Positive predictive value: $98.9 \%$ & & negative predictive value: $12.9 \%$ & & Accuracy: $77.6 \%$ \\
\hline
\end{tabular}

( $n=173$, Table 3 ). The results of the TIC based on the histology of the surgical specimens are shown in $\bullet$ Table 4.

\section{Data from the 15-year follow-up of patients} with a benign lesion (2013)

A surgical breast biopsy was avoided in 46 patients with 46 benign breast lesions as the histological result of the CNB as well as the result of the TIC were in agreement with the complementary breast diagnostics, and no lesion progression was found at the 3-, 6- and 12-month follow-up appointments after the interventional procedure.

The 15-year follow-up of the 46 patients took place in 2013 ( $\bullet$ Fig. 1); however 3 of these patients had died in the meantime. Other cancers or cardiovascular failure were present in these patients and breast cancer had not been the reason for death. Despite intensive research by the registry office and repeated letters, follow-up was not possible in 3 patients due to frequent changes of address.

Follow-up was carried out on 40 women. One patient underwent surgery after 27 months on a fibroadenoma with a significant progression in size ( $>50 \%$ ) which had been confirmed by histology and TIC. The histopathological result on the other hand showed a benign fibroadenoma measuring $2.1 \times 2.9 \times 3.8 \mathrm{~cm}$. Another patient (No.2) underwent surgical removal of a lesion, which she had described as being painful at the first diagnosis, 30 months after a diagnosis of "simple mastopathy" was made using CNB and TIC. The histopathological result was once again "simple mastopathy", measuring $1.4 \times 1.8 \times 2.2 \mathrm{~cm}$.

An invasive ductal, poorly differentiated breast cancer $(1.3 \mathrm{~cm})$ was detected using CNB in a third patient, 51 months after the ultrasound intervention. The patient subsequently underwent stage-appropriate oncological treatment. It should be emphasized that this very aggressive breast cancer was found $4.65 \mathrm{~cm}$ away from the fibroadenoma measuring $1.2 \times 1.1 \times 0.9 \mathrm{~cm}$ which was diagnosed at the time using ultrasound, CNB and TIC. It remained unchanged and was same size at the time of diagnosis of the invasive ductal breast cancer.

The fourth patient underwent surgery for an invasive lobular breast cancer 98 months after the interventional procedure in the area which had been diagnosed as "simple mastopathy" after CNB and TIC. The histological result was an invasive lobular breast cancer measuring $1.1 \times 0.9 \times 1.2 \mathrm{~cm}$, although this was a de novo breast cancer by definition because the previous intervention had taken place more than 8 years beforehand.

A sensitivity, specificity, positive, negative predictive value and diagnostic accuracy of $100 \%$ was found for the 40 primary benign lesions verified by CNB and TIC in a 15 -year follow-up. 


\section{Discussion}

\section{$\nabla$}

In German-speaking countries, the cytological evaluation of suspicious breast lesions has largely been displaced by histological examination procedures, especially the stereotactically-guided CNB.

However, the possibility of a rapid cytology-based test on cells obtained from stereotactically-guided CNB with subsequent histology combines the advantages of both methods. In the present evaluation, the long-term follow-up of primary benign lesions verified by CNB and TIC has been presented and showed excellent long-time follow-up.

The histological result of an intervention should preferably be available within a few days so that the oncological treatment can follow as soon as possible after the CNB [10]. In the 1990s, this approach was not viable in many institutions due to the physical distance between the clinic and pathology department; however this has changed, especially through the introduction of certified breast cancer centres. At that time, many hospitals had an experienced cytologist and ultrasound-guided aspiration cytology reached a sensitivity of $95 \%$, specificity of $91 \%$, and accuracy of $92 \%$ for the fine-needle aspiration procedure in the hands of the skilled $[23,24]$. The aim of our former investigation [16] was to find out to what extent TIC of stereotactically-guided CNB allows a sufficiently reliable and above all timely diagnosis. The results at that time showed much poorer sensitivity for cytological evaluation of TIC compared to the histological examination of the CNB (77.5 vs. 99.2\%). Because this, it was concluded that TIC is not an adequate method for the assessment of CNB.

Based on the results of our study, it already seemed to us at the time that the stereotactically-guided CNB was the more reliable method for clarification of mammary tumours, despite the good cytological results of other research groups.

Towards the end of the 1990s, 100 breast biopsy specimens were examined at the John Hopkins Bayview Hospital in a comparable study [19]. The sensitivity of touch imprints for malignant lesions was $92.3 \%$, whilst the specificity of imprints for benign lesions was $98 \%$. The positive predictive value of this test is $96 \%$, whilst the negative predictive value is $96.3 \%$. The accuracy of this test is also high at $96.2 \%$. Although their study demonstrates the accuracy and concordance of cytological touch imprints, the surgical follow-up data revealed that there does not appear to be any additive value to rendering a separate diagnosis on touch imprints of CNB.

A current German study [25] which investigated the validity and reproducibility of TIC of CNB in the assessment of conspicuous breast findings in 158 patients, showed good sensitivity, specificity, positive predictive value, negative predictive value and overall accuracy for $\operatorname{TIC}(99,100,100,94$, and 99\%). In addition, interobserver reproducibility was analysed und the inter-observer variability was very high (kappa-value of 0.8508 ; excluding inadequate imprints, 0.9502). Inadequate cellularity for cytological analysis was found in $11.4 \%$ (18/158) of findings. They concluded that TIC of CNB specimens of the breast may be a valid option for providing a diagnosis without delay for a histological procedure, assuming good quality of the specimen.

This last aspect leads to the limitation of our study in which all evaluable lesions of the patients, which were considered benign by TIC, did not show malignant deterioration in our 15-year follow-up. Nonetheless, one could argue that either the target of interest had been failed by stereotactically guided CNB, or the benign lesion at least camouflaged a cancerous or precancerous le- sion. In one case the histological type of the invasive breast cancer was an invasive lobular carcinoma. Particularly for this type of histology, false-negative results seem to be more frequent in other studies [25,26]. For benign tumours like fibroadenomas, the evaluation can also be difficult $[17,27,28]$. The cytological appearance of a rapidly-dividing fibroadenoma and papillomatosis are known to very closely resemble malignant cytology.

It has been suggested that TIC could also serve as a means of verifying the adequacy of biopsy specimens to optimize the biopsy procedure. Masood et al. [21] prospectively evaluated radiologically directed aspiration biopsy of non-palpable breast lesions and showed that use of a modified non-stereotactic localizing technique when combined with immediate microscopic evaluation resulted in a lower rate of inadequate samples (9\%), with a diagnostic accuracy of $96.7 \%$, sensitivity of $85 \%$, and specificity of $100 \%$. Jacobs et al. [17] showed that when immediate evaluation of CNB specimens is important, TIC can potentially decrease the number of biopsy passes required and provide preliminary diagnoses. Both studies conclude that touch imprints combined with stereotactic biopsy interpreted as part of an interdisciplinary approach can provide accurate information and that discrepancies, false-negative rates and false-positive rates can be reduced if both the cytological imprints and the cores are combined and diagnosed simultaneously. However, as mentioned above, Green et al. [19] reveal that rendering a separate diagnosis on imprints did not make any significant contribution. Cytological imprints may be helpful to the radiologist as a tool during an on-site evaluation; however their study showed that a separate cytological interpretation is unnecessary.

\section{Conclusion \\ $\nabla$}

TIC and stereotactically-guided CNB showed excellent long-term follow-up in our study. Therefore, the use of TIC to complement CNB can provide an immediate cytological diagnosis of breast lesions. The potential use of this technique in a certified breast cancer centre may help allay patient anxiety and expedite the planning of further surgical management. However, nowadays only few hospitals provide an experienced mammary cytologist why a nationwide coverage seems to be difficult. The implementation into routine practice and the limitations have to be evaluated in future studies.

\section{Conflict of Interest \\ $\nabla$}

None.

\section{Affiliations}

${ }^{1}$ Department of Gyn. Radiology, Institute of Diagnostic Radiology, University Hospital Erlangen, Comprehensive Cancer Center Erlangen-EMN, FriedrichAlexander-University Erlangen-Nuremberg, Erlangen, Germany

2 Department of Gynecology and Obstetrics, University Hospital Erlangen, Comprehensive Cancer Center Erlangen-EMN, Friedrich-Alexander-University Erlangen-Nuremberg, Erlangen, Germany

3 Institute of Pathology, University Hospital Erlangen, Comprehensive Cancer Center Erlangen-EMN, Friedrich-Alexander-University Erlangen-Nuremberg, Erlangen, Germany

4 Institute of Diagnostic Radiology, University Hospital Erlangen, Comprehensive Cancer Center Erlangen-EMN, Friedrich-Alexander-University ErlangenNuremberg, Erlangen, Germany 


\section{References}

1 Berg WA, Gutierrez L, NessAiver MS et al. Diagnostic accuracy of mammography, clinical examination, US, and MR imaging in preoperative assessment of breast cancer. Radiology 2004; 233: 830-849

2 Heywang-Koebrunner S, Bock K, Heindel $W$ et al. Mammography Screening - as of 2013. Geburtsh Frauenheilk 2013; 73: 1007-1016

3 Bukhari MH, Akhtar ZM. Comparison of accuracy of diagnostic modalities for evaluation of breast cancer with review of literature. Diagn $\mathrm{Cy}$ topathol 2009; 37: 416-424

4 NHS Breast Screening Programme No.50: Guidelines for non-operative diagnostic procedures and reporting in breast cancer screening. June 2001, ISBN 1871997445. Public Health, Gov. UK

5 NHS Breast Screening Programme No. 58: Guidelines for pathology reporting in breast disease. January 2005, ISBN 1844630153. Public Health, Gov. UK

6 Schulz-Wendtland R, Wenkel E, Imhoff K. Diagnostik von Brustdrüsenerkrankungen. Biopsiemethoden im Vergleich. GynäkolPrax 2004; 28 : 607-625

7 Ariga R, Bloom K, Reddy VB et al. Fine-needle aspiration of clinically suspicious palpable breast masses with histopathologic correlation. Am J Surg 2002; 184: 410-413

8 Boerner S, Fornage BD, Singletary $E$ et al. Ultrasound-guided fine-needle aspiration (FNA) of nonpalpable breast lesions: a review of 1885 FNA cases using the National Cancer Institute-supported recommendations on the uniform approach to breast FNA. Cancer 1999; 87: 1924

9 Pilgrim S, Ravichandran D. Fine needle aspiration cytology as an adjunct to core biopsy in the assessment of symptomatic breast carcinoma. Breast 2005; 14: 411-414

10 Kreienberg R, Albert US, Follmann $M$ et al. Interdisciplinary GoR level III guidelines for the diagnosis, therapy and follow-up care of breast cancer. Short version - AWMF Registry No.: 032-045OL. Geburtsh Frauenheilk 2013; 73: 556-583

11 Cross MJ, Evans WP, Peters GN et al. Stereotactic breast biopsy as an alternative to open excisional biopsy. Ann Surg Oncol 1995; 2: 195-200

12 Dahlstrom JE, Jain S, Sutton T et al. Diagnostic accuracy of stereotactic core biopsy in a mammographic breast cancer screening programme. Histopathology 1996; 28: 421-427

13 Schulz-Wendtland R, Krämer S, Döinghaus K et al. [Interventional techniques in breast diagnosis: ultrasound controlled puncture biopsy]. Aktuelle Radiol 1997; 7: 30-34

14 Berner A, Davidson B, Sigstad E et al. Fine-needle aspiration cytology vs. core biopsy in the diagnosis of breast lesions. Diagn Cytopathol 2003; 29: $344-348$
15 Dennison G, Anand R, Makar SH et al. A prospective study of the use of fine-needle aspiration cytology and core biopsy in the diagnosis of breast cancer. Breast J 2003; 9: 491-493

16 Hagedorn K, Krämer S, Mitze $M$ et al. [Interventional methods in breast diagnosis. Histological vs. cytological evaluation of core cut biopsies of the breast]. Aktuelle Radiol 1998; 8: 278-282

17 Jacobs TW, Silverman JF, Schroeder B et al. Accuracy of touch imprint cytology of image-directed breast core needle biopsies. Acta Cytol 1999; 43: $169-174$

18 Albert US, Duda V, Hadji P et al. Imprint cytology of core needle biopsy specimens of breast lesions. A rapid approach to detecting malignancies, with comparison of cytologic and histopathologic analyses of 173 cases. Acta Cytol 2000; 44: 57-62

19 Green RS, Mathew S. The contribution of cytologic imprints of stereotactically guided core needle biopsies of the breast in the management of patients with mammographic abnormalities. Breast J 2001; 7: 214218

20 Newman MR, Frost FA, Sterrett GF et al. Diagnosis of breast microcalcifications: a comparison of stereotactic FNA and core imprint cytology as adjuncts to core biopsy. Pathology 2001; 33: 449-453

21 Masood S, Feng D, Tutuncuoglu 0 et al. Diagnostic value of imprint cytology during image-guided core biopsy in improving breast health care. Ann Clin Lab Sci 2011; 41: 8-13

22 NHS Breast Screening Programme No. 22: Guidelines for cytology procedures and reporting in breast screening. September 1993, ISBN 1871997267. Public Health, Gov. UK

23 Dowlatshahi K, Gent HJ, Schmidt R et al. Nonpalpable breast tumors: diagnosis with stereotaxic localization and fine-needle aspiration. Radiology 1989; 170: 427-433

24 Killeen DM, Fraser F, Leinster SJ et al. The effect of stereotaxic fine-needle aspiration biopsy on the management of impalpable breast-lesions (Vol 3, Pg 173, 1994). Breast 1995; $4: 77$

$25 \mathrm{Kehl}$ S, Mechler C, Menton S et al. Touch imprint cytology of core needle biopsy specimens for the breast and quick stain procedure for immediate diagnosis. Anticancer Res 2014; 34: 153-157

26 Qureshi NA, Beresford A, Sami S et al. Imprint cytology of needle corebiopsy specimens of breast lesions: is it a useful adjunt to rapid assessment breast clinics? Breast 2007; 16: 81-85

27 Klevesath MB, Godwin RJ, Bannon R et al. Touch imprint cytology of core needle biopsy specimens: a useful method for immediate reporting of symptomatic breast lesions. Eur J Surg Oncol 2005; 31: 490-494

28 Sneige $N$, Tulbah A. Accuracy of cytologic diagnoses made from touch imprints of image-guided needle biopsy specimens of nonpalpable breast abnormalities. Diagn Cytopathol 2000; 23: 29-34 